\title{
Article
}

\section{TPACK of Prospective Mathematics Teachers at an Early Stage of Training}

\author{
Yuri Morales-López *, Yerlin Chacón-Camacho and Wilbert Vargas-Delgado
}

\footnotetext{
check for updates

Citation: Morales-López, Y.;

Chacón-Camacho, Y.;

Vargas-Delgado, W. TPACK of

Prospective Mathematics Teachers at

an Early Stage of Training.

Mathematics 2021, 9, 1741. https:/ /

doi.org/10.3390/math9151741
}

Academic Editor: Marta Molina

Received: 11 June 2021

Accepted: 21 July 2021

Published: 23 July 2021

Publisher's Note: MDPI stays neutral with regard to jurisdictional claims in published maps and institutional affiliations.

Copyright: (C) 2021 by the authors. Licensee MDPI, Basel, Switzerland. This article is an open access article distributed under the terms and conditions of the Creative Commons Attribution (CC BY) license (https:/ / creativecommons.org/licenses/by/ $4.0 /)$.
Escuela de Matemática, Facultad de Ciencias Exactas y Naturales, Universidad Nacional, Heredia 86-3000, Costa Rica; yerlin.chacon.camacho@est.una.ac.cr (Y.C.-C.); wilbert.vargas.delgado@est.una.ac.cr (W.V.-D.)

* Correspondence: ymorales@una.cr

\begin{abstract}
The objective of this work is to present the results of an investigation on the technological, pedagogical and content knowledge evidenced by mathematics teachers in the second year of initial training (preservice) at the Universidad Nacional, from the TPACK model perspective, on the subject of functions. The research has a qualitative approach with an interpretive hermeneutical stance. A sample of 27 teachers in training who were enrolled in courses related to the three base domains of the TPACK model (pedagogical, technological and content of quadratic function) during the first semester (I cycle) of 2020 was used. Three instruments with situations involving the quadratic function were created to determine students' knowledge. They were also asked to design their own situation to teach an element linked to this topic, which was then shared and evaluated by their peers. The results show that participants possess instrumental dominance over the basic forms of knowledge underlying the model. It is concluded that, although participants have already experimented in courses related to these forms of knowledge, there is insufficient evidence to ascertain that their current knowledge would allow them to integrate technologies as a didactic resource within the teaching of the subject of quadratic function.
\end{abstract}

Keywords: functions; knowledge organization systems; Mathematics Education; teacher training; TPACK

\section{Introduction}

The use of technology is present in various areas of human endeavor and the educational process is no exception. Researchers such as Bonafini and Lee [1] affirm that the use of technologies can be a great ally; however, it is vital to understand that by itself it does not achieve a significant change. Consequently, multiple investigations have been conducted focused on studying the integration of technological tools in the mathematics class.

The core point of the teaching process is to understand that the content (in this case, mathematics) and its pedagogy are inseparable, and teachers must possess specialized knowledge that transcends these two areas of knowledge [2,3]. In the case of Mathematics Education, the teacher must not only know mathematics and pedagogy, but also how to teach this discipline.

Furthermore, the implementation of Information and Communication Technologies (ICTs) within mathematics classes must be intelligent, relevant and pertinent. Therefore, investigating the possible technological integration carried out by teachers during their training is of importance, since it is based on the premise that, even when a teacher possesses extensive knowledge in technologies, this does not empower him/her to achieve a correct integration of ICTs within teaching spaces. In addition, Bonafini and Lee (2021) indicate that "the pressure for integrating technology into teaching also makes latent the demand for pre-service mathematics teachers to use technology in their classrooms" ([1], p. 303). This is similarly apparent in [4]. 
Moreover, McBroom [5] states that teachers tend to teach in the same manner they were instructed. If this statement is correct, an early introduction of methodological strategies that involves the use of technology with teachers in initial training preservice teachers should be attempted, as this can have an impact on their use during their teaching practices.

Thus, for us, it is relevant to analyze whether the training provided to mathematics teachers at the Universidad Nacional (UNA) in Costa Rica is generating the capacities in preservice mathematics teachers for the efficient integration of technology in the teaching and learning process, and in particular, it is of interest to know what happens in the early stages of this training.

From the literature that has been reviewed for the present study on initial teacher training (e.g., [2-13]), it was decided to use the Technological Pedagogical Content Knowledge (TPACK) model and relate it with the subject of teaching functions. Functions are used in various areas of mathematics and allow the modeling, quantification or description of natural phenomena or daily activities. It is necessary for the mathematics teacher to know about the subject and, when the context permits, be able to relate the elements of a specific context (situation) with a possible function beyond mathematical content as such.

In this way, the interest arises to carry out a study to determine what are the technological, pedagogical and content forms of knowledge exhibited by mathematics teachers in initial training at the Universidad Nacional regarding tasks in the area of mathematics on the subject of quadratic function based on the study of the TPACK model.

To achieve this, the following objectives are established:

(1) Investigate the technological, pedagogical and content knowledge evidenced by mathematics teachers in initial training, when solving a mathematical task in the subject of quadratic function.

(2) Design or adapt a mathematical task in the subject of quadratic function that integrates technological, pedagogical and content knowledge, using the TPACK model.

(3) Describe the technological, pedagogical and content knowledge of the subject of quadratic function possessed by mathematics teachers in initial training, within the framework of the TPACK model.

This study is relevant as it can provide information on how teachers configure the different knowledge they acquire in the areas of mathematics, pedagogy and technology separately at an early stage and whether knowledge in these three areas really stimulates teachers' abilities to integrate their discipline knowledge, pedagogy and the use of technology into a single body or system of knowledge. That is, whether these areas are really integrated or whether special training is needed to be able to use technology efficiently. As Backfisch et al. [10] indicate "to-date there is only limited empirical evidence on the factorial structure of these technology-related knowledge components and how these components are related to each other".

\section{Conceptual Framework}

Over the years, the teaching of mathematics has been seen as the transmission of mathematical knowledge; however, teacher training has been focused in various ways in order to meet the demands presented by society at a given moment.

Various authors such as [1-5] point out that it is essential for teachers to possess the capacity to mediate in the classroom and for them not to have as the mere objective the simple transmission of knowledge. Faced with the interpretation of what an adequate mediation represents, various trends have emerged in teacher training that, with scientific foundation, direct teacher instruction practices, with the objective of explaining and improving education. In the case of mathematics, Reference [14] affirms that the trend towards the presentation of contextualized mathematics has been incorporated with the aim of "presenting a situation of extra mathematical context that is understood by the student as a particular case of a mathematical object" ([14], p. 26); thus, it is essential that in teacher will training the skills necessary to approach mathematics from a contextualized 
perspective be developed. Godino et al. [15] affirm that it is necessary for mathematics teachers to be able to analyze the teaching and learning processes and add that it is necessary to train teachers to make an adequate selection of didactic knowledge to improve the design, implementation and evaluation of teaching practice.

\subsection{Identification of Technological, Pedagogical and Content Knowledge in Teacher Training}

There are different systems that allow organizing mathematical knowledge for teaching; the Technological Pedagogical Content Knowledge (TPACK) model proposed by Mishra et al. [16] in 2006, emerged as a theoretical foundation for research in the area of educational technology. The model describes the forms of knowledge that teachers must possess to effectively integrate technological tools in the teaching process (references to other models can be found in Morales-López [17]).

This archetype is based on the theoretical foundations on pedagogical knowledge of $[2,3]$ and with the incorporation of ITCs in education the idea arises that knowledge about pedagogy, content and technology are linked to each other. From this approach, technological knowledge is a fundamental knowledge of the teacher and should not be understood as something separate from pedagogical and content knowledge [16].

The model considers pedagogical knowledge (PK), content knowledge (CK) and technological knowledge (TK) as bases or principal domains but also considers the relationships or interactions that exist among them; according to Mishra et al. [16], "our model of technology integration in teaching and learning argues that developing good content requires a thoughtful interweaving of the three key sources of knowledge: technology, pedagogy and content" ([16], p. 1029). These relationships give origin to technological pedagogical knowledge (TPK), pedagogical content knowledge (PCK) and technological content knowledge (TCK), from which technological pedagogical content knowledge (TPACK) is driven. These domains are described below.

1. Content Knowledge $(\mathrm{CK})$ must be had on the subjects, concepts and theories. It includes understanding the subject, knowing different explanations for a given subject and providing the ideas that evidence proof of knowledge [16].

2. Pedagogical knowledge $(\mathrm{PK})$ is related to the necessary processes and practices for adequate teaching and learning. It refers to classroom management, class planning, and learning evaluation. It contemplates understanding how students learn and develop desired skills [16].

3. Technological knowledge (TK) refers to the skills to operate technologies in the teaching process, from the most common to more advanced digital technologies [16].

4. Technological-pedagogical knowledge (TPK) arises when carrying out pedagogical activities using technological tools. It includes knowing how teaching can change due to the use of technology; it also involves knowing a variety of technological tools that can help develop a certain topic and knowing how to choose the appropriate tool to mediate it. In addition, it includes knowing methodological strategies to be able to address content through the use of technology [16].

5. Pedagogical content knowledge (PCK): "PCK deals with the representation and formulation of concepts, pedagogical techniques, knowledge of what makes concepts difficult or easy to learn, knowledge of students' prior knowledge, and theories of epistemology" ([16], p. 1027). Thus, a teacher with a developed PCK and who comprehends the characteristics of his students knows how to use activities in each subject content to help them learn. This knowledge makes it possible to identify the errors that students usually present in each topic and how to correct them. This knowledge agrees with PCK [2,3].

6. Technological content knowledge (TCK) is the knowledge that allows the use of technology to represent content and encompasses knowing how to use technology in a way that improves understanding of the matter and also favors and facilitates the different representations of the content [16]. 
7. Technological pedagogical content knowledge (TPACK) is a form of knowledge that arises from all the previous relationships and that, as a unit, possesses a greater scope than the any of the three individual basic forms of knowledge [16]. The authors affirm that TPACK includes knowing "... pedagogical techniques that use technologies in constructive ways to teach content; knowledge of what makes concepts difficult or easy to learn and how technology can help redress some of the problems that students face" ([16], p. 1029); the authors add that this subdomain involves knowing how technologies can be used in constructivist teaching methods.

Any change that occurs in one of the domains or subdomains of the model must be leveled by a change in the rest, because all the elements of the model are in a dynamic equilibrium of essential tension ([16], Figure 1).

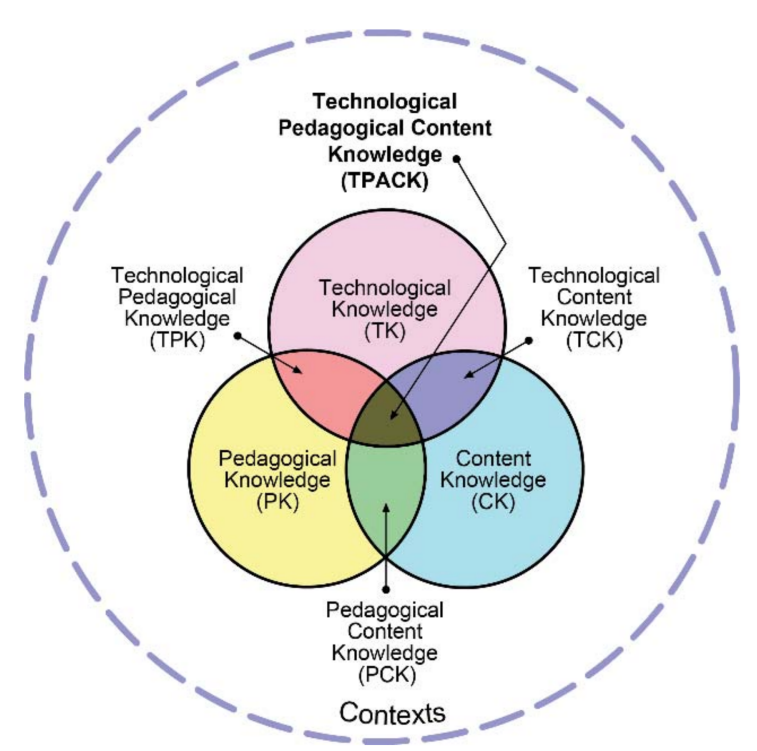

Figure 1. TPACK framework and its knowledge components. The TPACK Image (rights free, from http:/ / www.tpack.org/ (accessed on 15 February 2020)).

The introduction of this model requires including spaces in the training process in which future teachers are made aware of the importance of appropriation of technological resources and where, through different work methodologies, routes other than the traditional ones can be explored.

The TPACK model is a tool that has the ability to impact class methodology through the knowledge that teachers possess and the perception of the subject. However, technology does not solve all learning problems, and proper timing and purpose for its inclusion in class activities should be analyzed [18]. From this stance, to integrate ICTs in mathematics classes, pedagogical practices must be reorganized to guarantee interaction and integration of the three forms of knowledge.

Studies carried out using the TPACK model confirm that using ICTs in teaching is not a mechanical process; for example, research such as the one carried out by Kirikçilar et al. [19] assures that mathematics teachers have difficulties using GeoGebra within the TPACK frame, furthermore, Arévalo-Duarte et al. [20] state that students perceive these difficulties and question the competencies of their teachers in the use of different types of technologies.

Despite these difficulties, some investigations have determined that participants perceive a great difference between teaching with and without technologies [21] and "the preservice teachers' experiences could be good preparation for them before they enter the teaching service" ([8], p. 10). For example, with the help of GeoGebra software, students are able to understand abstract concepts, as they are provided with a visual idea of what is studied [19]. In any case, "pre-service teachers should be exposed to technological tools (i.e., 
simulations, virtual laboratories, digital educational games) in teacher education programs to develop their TPACK and be able to integrate technology in their courses in the future" ([9], p. 19). Other examples of this affirmation can be found at [10-13].

On the other hand, measuring TPACK has been a difficult process to engage in; Koehler, Shin and Mishra [22] determined that in most of the works that use only observation and interviews, evidence was inconclusive about the validity of the instrument, and this represents the urgency for a study like the one carried out here.

\subsection{General Elements on the Subject of Function, Its Representations and Its Teaching}

Knowing the different representations of the concept of function allows for the characterization of knowledge since it reveals the relationships among different representations and the meaning of mathematical concepts.

Duval [23] defines a semiotic representation as "productions constituted by the use of signs that belong to a representation system, which has its own constraints of significance and functionality" ([23], p. 39). Semiotic representations of a mathematical object or concept are totally necessary, since many mathematical objects are not accessible via a visual or other type of idea that would facilitate their understanding [23].

Various authors have determined that the transformation of semiotic representations is a process of cognitive complexity that guides the understanding of a mathematical content [23], in addition, it favors the understanding of concepts [24].

On the subject of functions, authors indicate that it is preferred to work with the algebraic representation [25] and that frequently the necessity of realizing the transformation of semiotic representations is not understood, specifically the transformation from algebraic to tabular or graphic [26].

Therefore, it is important that preservice teachers master the semiotic representations and the transformation among them, as this facilitates understanding. In addition, it is valuable for teachers to face the execution and planning of educational practices related to different representations in order to break with traditional schemes.

Regarding the difficulties in addressing the subject, the study of functions presents obstacles in the teaching and the learning processes that are part of the pedagogical knowledge of the content that teachers must acquire during their initial training.

A limitation in teaching of functions is that, traditionally, exercises are performed in a mechanical and decontextualized manner. Various investigations coincide that these problems are due to the cognitive complexity of the content and inadequate pedagogical intervention, which increase the degree of difficulty [26].

Artigue [27] summarizes the following difficulties for the learning of functions: "difficulties related to the identification of what a function really is and the recognition that the sequences are also functions" ([27], p. 3) and "difficulties to transcend the modes of numerical and algebraic thinking" ([27], p. 4). Artigue [27] adds that it is necessary to prevent the student from losing the true meaning of function depending on the semiotic representation that student uses. For his part, Díaz [28] considers that errors and difficulties in learning functions occur in the following four areas: "not considering the domain and range of functions, a tendency for regularity, a punctual approach (in graphs) and a separation between the graphic and algebraic context" ([28], p. 38).

Elia et al. [29] point out the existence of difficulties in providing an adequate definition of the concept of function, since students focus only on the algebraic expression, forgetting the domain and range, and according to Díaz [29], the above issues cause errors in the construction of graphic representation.

Under the same perspective, Córdoba et al. [30] mention that students have problems understanding the relationship of the coefficient of the linear term with the position of the axis of the parabola, nor do they relate the coefficient of the quadratic term with the information provided by the graph. The authors add that problems are presented with greater intensity if the starting representation is a graph. 
Future mathematics teachers are unable to convey a connection among the different representations of the quadratic function, which makes difficult its study because more extensive procedures are carried out than necessary [31]. Another situation that usually occurs is that the relationship between the coefficient of the quadratic term with concavity is taught as a rule, therefore making it difficult for students to understand the relationships between the main coefficient of an algebraic expression and its graphic representation [31].

Moreover, it is difficult to understand and imagine that the parabola extends infinitely, and confusion occurs with properties of functions and quadratic equations as pointed out by González [32]. In the study carried out by $\mathrm{Hu}$ [33], it was determined that teachers perform better when they change the register of representation of the quadratic function than they do when solving real-world problems using the quadratic function; in addition, difficulty was shown on conceptual understanding of quadratic functions.

From the above, it is understood the need to develop in future mathematics teachers the necessary competencies to address problem solving and develop pedagogical strategies that will respond to the attention of students' difficulties and errors.

\section{Methodology}

The purpose of the present study is to characterize the technological, pedagogical and content knowledge exhibited by mathematics teachers in initial training at UNA at an early stage of training. For this reason, the study is framed in the naturalistic paradigm since it contemplates approaching social reality, understanding and transforming it [34]; the research is framed within the qualitative approach, because " ... it produces descriptive data: people's own words, spoken or written, and observable behavior" [35]. Likewise, the investigation is carried out from an interpretive hermeneutical stance since interpretations are made on the information provided by mathematics teachers in initial training.

The study had the participation of 27 students enrolled in the course, MAC404 Computer Resources, belonging to the study plan of the undergraduate program Bachillerato y Licenciatura en la Enseñanza de la Matemática BLEM (2017) (translated as Bachelor and Licentiate Program in Mathematics Teaching BLEM (2017)), during the I cycle of 2020. The participants are in the second year of their studies and, according to the training program, have completed in that first year two courses of the mathematics component (CK of 4 credits each), two courses of the pedagogical component (PK of 4 credits each), two courses of English (4 credits each) and four courses of general subjects ( 3 credits each). As indicated, participants are in the first semester of the second year and must regularly have enrolled in two mathematics courses (CK of 4 credits each), two pedagogical component courses (PK of 4 credits each) and one instrumental course on the use of technology (TK of 4 credits).

As criterion for selection, considered participants must have approved or be enroll in, during the mentioned scholar cycle, the courses DEY402 Pedagogical models and learning theories (Pedagogical Knowledge), MAC403 Principles of mathematics II (Mathematical Knowledge), MAC404 Computer resources (Technological Knowledge) from the second year, since these courses are related to the bases (principal domains) of knowledge present in the TPACK model and the subject of functions. In the present study, participant individuals are collectively denominated Mathematics Teachers in Initial Training (MTIT).

The development of the investigation began with a literature review that allowed the recognition of the bases of the TPACK model in the works of the authors Mishra and Khoehler [16]; other studies related to this model were also searched in specialized databases (i.e., Scopus and Web of Science). Bibliography was consulted regarding teaching of mathematics (specifically functions), semiotic representations, training of mathematics teachers and use and importance of technologies in teaching, both nationally and internationally. Additionally, a short study was carried out on the instruction of teachers trained in public universities in Costa Rica on the subject of functions, in order to have a global idea of the context.

Categories of analysis were defined based on the forms of knowledge proposed by the TPACK model. Along with this, the majority of investigations found and related to 
the TPACK model focus on mathematical contents other than the subject of functions. For this reason, international studies carried out $[19,20,36]$ served as the basis for designing a list of units of analysis corresponding to each category, and others were included from the literature review. Other models have also been developed and oriented in specific contexts (e.g., [12]).

The units of analysis that were used to characterize each category (knowledge of the MTIT in relation to TPACK) are presented below. These categories represent one of the main contributions of the present investigation:

- Pedagogical Knowledge (PK)

PK1. Selects aspects that influence the teaching and learning process.

PK2. Possesses knowledge of various methodological strategies for teaching and learning mathematics.

PK3. Argues about the potential offered by the various methods and strategies available for teaching and learning mathematics.

- Technological Knowledge (TK)

TK1. Is able to solve technical problems [36].

TK2. Assimilates technological knowledge easily [36].

TK3. Keeps up to date on new technologies [36].

TK4. Possesses knowledge of many different technologies [36]

TK5. Has had sufficient opportunities to work with different technologies [36]

TK6. Feels comfortable using technology.

TK7. Expresses that he/she often plays with and tests technology [36].

TK8. Possesses technical knowledge required to use technology [36].

- Content Knowledge (CK)

CK1. Provides an adequate definition of the concept of quadratic function.

CK2. Is able to find the algebraic expression that describes the presented situation.

CK3. Determines specific elements of the quadratic function.

- $\quad$ Technological Pedagogical Knowledge (TPK)

TPK1. Selects technologies that can facilitate the teaching and learning of the quadratic function.

TPK2. Reflects on how technology influences learning of the subject of quadratic function.

TPK3. Adopts critical thinking about how to use technology in the classroom [36].

TPK4. Promotes learning activities wherein students manipulate technological tools [32]. TPK5. Suggests technological tools that contribute to the development of knowledge and skills relevant to the quadratic function.

TPK6. Represents real situations using software.

- Pedagogical Content Knowledge (PCK)

PCK1. Correctly interprets the elements of the quadratic function according to the context.

PCK2. Designs activities on quadratic function that favor the conceptual and procedural development of students [20].

PCK3. Proposes activities that begin with general or simple aspects to later expand into formal or more complex aspects.

PCK4. Clearly manifests the existing relationship between the representations of the quadratic function.

PCK5. Understands the scope of teaching and learning of the subject of quadratic function in secondary education (high school).

PCK6. Proposes to address the teaching-learning stages established by the current study program. 
PCK7. Is aware of the errors that students present regarding the understanding of the quadratic function.

PCK8. Applies information associated with real life in the design of an activity [19].

PCK9. Designs activities where the different representations of the quadratic function are used appropriately.

\section{- $\quad$ Technological Content Knowledge (TCK)}

TCK1. Possesses knowledge about technological resources that can be used to develop the subject of quadratic functions.

TCK2. Interprets the basic concepts of the quadratic function through a representation provided by software.

TCK3. Uses animations and graphic drawings to enrich his/her mathematical activity proposal.

TCK4. Uses computer installed software for mathematical purposes (for example, Excel, GeoGebra, RStudio, Sketchpad, Winplot, etc.)

TCK5. Searches the Internet for reliable concepts or information related to the quadratic function.

TCK6. Considers that there are advantages and disadvantages in using technological resources for teaching mathematics.

- $\quad$ Technological Pedagogical Content Knowledge (TPACK)

TPACK1. Effectively integrates mathematics, technology, and pedagogy in planning an activity for teaching quadratic functions.

TPACK2. Uses the most appropriate semiotic representation to teach aspects of the quadratic function by means of a technological tool.

TPACK3. Possesses knowledge about appropriate technologies for teaching functions, how to use them and their influence on the teaching process.

TPACK4. Possesses the ability to use technological devices to measure students' preliminary knowledge of mathematical content [37].

TPACK5. Knows how to use technological devices that allow identifying the difficulties presented by students in learning quadratic functions.

Once each category had been determined with its units of analysis, the construction of three instruments for the collection of information was initiated, so that each question would allow to analyze at least one unit of analysis. The first Diagnostic Questionnaire was created to inquire about the technological and pedagogical knowledge evidenced by MTITs and to learn about their general data; it consists of 17 questions where some are adapted from the instruments used $[19,20,36]$ (Supplementary Materials 1).

The second instrument, Assignment of Mathematical Tasks, was constructed thanks to the theoretical investigation carried out and is composed of different mathematical tasks about the quadratic function that allow to evidence MTITs' knowledge on TPACK. Two contextualized situations are proposed denominated Situation 1 and Situation 2, adapted from the material constructed [38] for the course MAC403 Principles of Mathematics II. This instrument allows MTITs to show their mastery of official study programs, GeoGebra software and quadratic function content. As a final activity, MTITs should pose a situation to address this subject (content) using GeoGebra directed to a secondary education (high school) audience and also create the instructions to guide the student in the development of the activity (Supplementary Materials 2).

In the third instrument Reflection on the Analysis of Instructions, each MTIT was assigned to reflect on the activity proposed by another colleague generated in the instrument Assignment of Mathematical Tasks; by reflection is meant the creation of a comment with justified ideas or positions to improve the quality of the activity, and to share the comment in a forum created on a Moodle platform. This stage relates to TPACK knowledge because MTITs must reflect on how the organization of the activity and the instructions created may influence the learning of the subject (Supplementary Materials 3). 
The instruments constructed and the units of analysis used in this work were subjected to a validation process with three experts in pedagogy, technology and mathematical content of functions (one person of each area); all have previously worked on knowledge organization systems of mathematics teachers and didactics of mathematics. Each of these specialists has more than 15 years of experience and publications in their area of expertise. To carry out this process, validation instruments were constructed and applied in two stages, three months prior to the application of the instruments; in the first stage, the units of analysis and the Diagnostic Questionnaire were validated; in the second stage, the Assignment of Mathematical Tasks and Reflection on the Analysis of Instructions were validated. In this way, an additional assessment of each of the above-mentioned instruments was constructed. It was mainly structured with open-ended questions in order to get the experts' opinions. Each question was followed by a request to expand the description with possible answers and interpretations of the questions.

The examination of the collected information was performed following content analysis [39] as this technique is characteristically objective and permits reproducing the collection of information for data verification. In addition, the systematization of this technique procures to encompass the totality of the content studied. Furthermore, the study of the collected information proposes to expand from the mere interpretation of the manifest content and delve into the social context from where the information is collected $[40,41]$.

Continuing with the content analysis process, once the system categories had been established, tables were designed to show the relationship between the units of analysis and each item in the proposed instruments. To ensure the validity of the results obtained from the investigation, the triangulation method was employed [42]. For the purposes of this study, two of the types were considered: method triangulation and data source triangulation. Emphasis was placed on contrasting the information obtained from the literature with that of the experts. In addition, different databases were consulted to obtain a variety of resources for different approaches to research on this topic.

\section{Results}

The analysis of information is presented organized with respect to each collection instrument, and data are systematized according to each domain of the TPACK model.

\subsection{Diagnostic Questionnaire}

\subsubsection{Technological Knowledge}

The majority of MTITs expressed good self-perception of their TK in terms of assimilation of new technological knowledge (TK2) and comfort when using ICTs (TK6), which indicates the existence of a positive attitude toward the use of technology. However, most MTITs are in disagreement or undecided (option "N = Neither disagree nor agree") when specifying aspects related to experimenting with technology (TK7), possessing the necessary technical knowledge to effectively use technological resources (TK8) and solving basic problems in the technological field (TK1).

\subsubsection{Pedagogical Technological Knowledge}

MTITs express that the most appropriate software to consider in teaching and learning processes involving quadratic functions (TPK1) are YouTube and GeoGebra. It should be noted that, although YouTube is not a technological tool created specifically for educational purposes, almost all MTITs rated it as one of the best options. Similarly, ten participants consider applications such as PhotoMath, Mathway or Socrative, Power Point presentations and graphing calculators to be useful for teaching. Furthermore, most MTITs do not know how to use software such as Winplot, Wolfram Alpha, RStudio, Sketchpad and Mathematica, employed in current higher-level courses of teacher training, which could explain their present lack of acquaintance. 


\subsubsection{Pedagogical Content Knowledge}

Errors that can be found in the teaching and learning processes of the quadratic function, according to the criterion of MTITs (PCK7) are: (1) identification of the function criterion; (2) knowing how the graphic representation of the quadratic function changes upon modifying coefficient constants $a, b$ and $c$ of the function criterion; (3) difficulty in the analysis of the quadratic function due to inability to solve second degree equations and (4) the concept of function is not clear.

\subsubsection{Technological Content Knowledge}

As previously indicated, MTITs evidenced knowledge of certain technological resources (specific software or tools) that could be used in the classroom to develop the subject of functions (TCK1). In addition, twenty-six MTITs stated that they use technological tools with access to the Web to investigate about mathematical content that they do not know (TCK5).

The advantages of using technology in the mathematics class (TCK6), according to the participants are: (1) facilitates the visualization of mathematical objects; (2) captures the attention of students due to its versatility; (3) saves time and (4) diversification of methodologies, among others. On the other hand, participants identify as disadvantages (TCK6) the fact that technology can be a potential factor for student distraction and that its incorrect application can hinder teaching and learning processes.

\subsubsection{Technological Pedagogical Content Knowledge}

MTITs point to aspects where the implementation of ICTs can be influential (TPACK3), for example, fourteen participants indicate that ICTs improve the visualization process and facilitate the understanding of changing semiotic representations. Likewise, five MTITs consider that a correct implementation of technology allows classes to be more interactive, illustrative and entertaining. Additionally, they recognize that adequate technological implementation depends on the teacher's execution.

\subsection{Assignment of Mathematical Tasks}

\subsubsection{Pedagogical Knowledge}

The majority of MTITs $(n>22)$ considered the main influencing aspects on the learning process to be (PK1): (1) classroom condition (lighting, ventilation, appropriate seats, etc.); (2) assertive teacher-student communication and vice versa; (3) relevant teaching resources (adequate and sufficient) and (4) teacher's knowledge on the subject. In addition to the above, MTITs mentioned that student attitude, the coexistence environment, learning strategies, health and socioeconomic status also influence the teaching and learning processes.

Regarding PK2 and PK3, MTITs argued that the pedagogical models that they would use when teaching mathematics are: collaborative work (eight), constructivist model (four), problem solving (four), cognitive model (three), a combination of pedagogical models (seven) and lectures (one). In addition, in the instrument they mentioned some benefits of using these models.

\subsubsection{Content Knowledge}

Only five participants provided a correct definition function (CK1) mentioning the domain, range and criterion. The rest focused on the association criterion or included elements that are not directly related to the definition. In addition, seventeen MTITs were able to correctly determine the criterion of a quadratic function (CK2) that described Situation 1, and eleven participants identified images and their respective preimages within the context (CK3):

Situation 1. The entrance to a building is $2.25 \mathrm{~m}$ high in the center, $3 \mathrm{~m}$ wide at the base and has the shape of a parabolic arch. 
Along the same lines, most MTITs are knowledgeable that the vertex represents the extreme point of the function and of the relationship it holds with monotony and the axis of symmetry. In addition, eighteen participants determined the domain of the function as $\mathbb{R}$, of which only two provided the correct interval in accordance with the context presented in Situation 2. Nine considered an unbounded interval as the range, while four as bounded:

Situation 2. A function that models the height, in meters, of a baseball thrown by a child has as its criterion of association $f(x)=-1 / 3 x^{2}+3 x+1.83$, where $x$ is the horizontal distance (in meters) from where the ball was thrown.

\subsubsection{Technological Pedagogical Knowledge}

It was observed that most of the participants managed to graph quadratic functions using GeoGebra software. In Situation 2, eight of the participants labeled the point on the graph as "ball", highlighted it with another color, increased its size, and even inserted images of a ball and other elements (TPK6).

After working on Situation 2, they were asked to create a situation of their own design. Most participants used quadratic functions that adequately model the situation they proposed. Similarly, six MTITs suggested graphing a quadratic function with parameters and assigning sliders for each parameter to guide the deduction of properties between the graphic and algebraic representations. Below are two animations made by the participants (Figures 2 and 3).

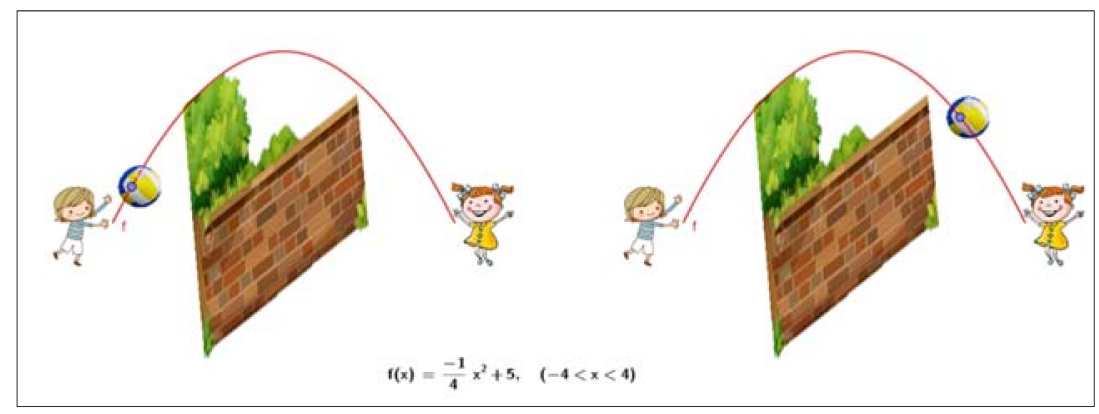

Figure 2. Participant 9; mathematics task assignment, item 15a.

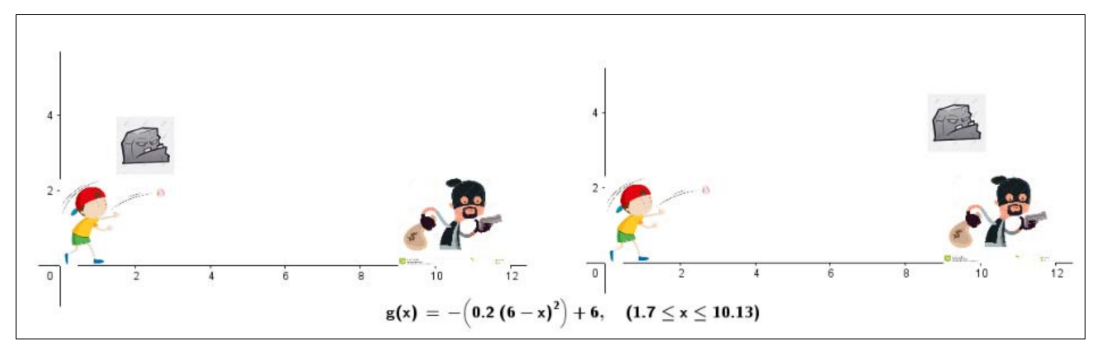

Figure 3. Participant 25; Mathematics task assignment, item 15a.

\subsubsection{Pedagogical Content Knowledge}

Regarding the unit of analysis PCK1, MTITs were knowledgeable in determining images and preimages within a context (eleven), interpreting the domain and range of the function according to the situation (twelve), interpreting the coordinates of any point in the graph of the function (fourteen) and determining the axis of symmetry (seventeen), although some participants gave the wrong interpretation of this.

Furthermore, according to MTITs, the approach to the subject of quadratic function in tenth grade of secondary education (high school) in Costa Rica is taught superficially and many MTITs agreed that it focuses on the analysis of the graph based solely on its criterion (PCK5). Participants assure that to teach this subject in secondary education, they would develop an activity, outdoors or inside the classroom, involving an experiment related to 
the function (thirteen); others say they would use software, mainly GeoGebra (eleven); and a few state that they would first provide a lecture to assign practices (PCK6).

Regarding the design of the activity, almost all participants attempt to favor the conceptual development of the quadratic function (PCK2) in aspects such as concavity, intersections with the axes, axis of symmetry, vertex, domain and range. However, only a small portion of MTITs promoted the incorporation of the latter aspects in the procedural development of this subject in their activities (the vast majority did so in a way without order or a justified intention). Furthermore, only five MTITs posed questions that progressively increased their degree of difficulty with the purpose of generalizing concepts (PCK3). Even though what was presented by MTITs was inadequate, it is evident that most participants proposed non-traditional situations and chose quadratic functions attempting to adjust quite well to reality (PCK8).

It is important to indicate that nine participants request in their activity to explicitly establish how the graphic representation changes with the variation of the values of the coefficient constants of the function criterion, which is related to the proper use of the different semiotic representations (PCK9).

\subsubsection{Technological Content Knowledge}

It was evidenced that twenty participants created a correct representation in the software to describe the context presented in Situation 1; in the case of Situation 2, all participants realized the representation of the parabola that describes the movement of the ball, simulating the ball by a point that moves along the trajectory, although only ten MTITs considered the correct function domain. In addition, MTITs utilized point animations and image insertions in GeoGebra to enrich their representation (TCK3). It should be noted that only eleven participants correctly interpreted the representation of Situation 1 to answer a question related to the context. Likewise, for Situation 2, only fifteen MTITs managed to relate the coordinates of a given point on the graph with the context (TCK2).

\subsubsection{Technological Pedagogical Content Knowledge}

The TPACK1 unit of analysis is reflected in the activities proposed by seven MTITs since they (1) prepared a detailed technical instruction guide to allow students to work with GeoGebra software, (2) employed a function that is appropriate to the proposed context, (3) formulated questions with clarity that allow students to relate the context with the mathematical concept through visual support and software manipulation (graphic representation), (4) constructed exercises to evidence the relationships that exist between the graphic and algebraic representations of a quadratic function and (5) formulated questions to guide students to reach generalizations of the properties of quadratic functions. Hence, there is explicit evidence that these MTITs attempted to favor the conversion between semiotic representations, which is related to the TPACK2.

\subsection{Reflection on the Analysis of Instructions}

\subsubsection{Technological Pedagogical Knowledge}

Fifteen participants mention ways in which technology influences the learning of the subject of quadratic function (TPK2). For example, that GeoGebra allows to (1) visualize function related concepts, (2) motivate students and (3) implement activities to explore this subject. MTITs also recommended the inclusion of images, both in the illustration of the problem statement and student instruction guides for performing software simulation. In addition, seven MTITs evidenced this knowledge as they recommend inclusion of images to guide students in the use of GeoGebra, elaboration of more specific instructions regarding the use of software functions and to guide the student to optimize the process of deducing function properties (TPK3). 


\subsubsection{Technological Pedagogical Content Knowledge}

Regarding TPACK knowledge, only three participants posted forum comments that made possible to relate their knowledge to analysis unit TPACK1.

For example, a participant directs his comments towards making an effective integration of mathematical content, technology and pedagogy, as he reflected on the quality of the format, the presentation of the document and what this could involve at the time of execution. Later, the MTIT reflected on the idea that the order of the document can influence its comprehension. The participant demonstrated his/her pedagogical content knowledge by suggesting that the inclusion of images helps the student relate the situation to the mathematical content. Regarding TPACK knowledge, this participant proposes to improve the visualization of the context (TPACK1).

For example, the following are the suggestions made by participant 20 to the instructions designed by another of his peers. (1) Try to put the title of the topic to be addressed, this is used as a heading and denotes a greater formality in the structure of any educational material or document; (2) Take care of the wording, put the relevant indentations and try not to use words that sound redundant, (3) It is very important that you list the questions, or that there is a bullet point, indicating that you are separating the problem statement on the questions; (4) I think it is important that you try to include an image related to the problem, as this would be a useful aid for the student to be able to relate more easily to the problem posed, and don't forget to leave a space after each question for the student to write his or her answer. (5) You can also integrate other aspects of the quadratic function in this exercise, for example, in which interval it grows or decreases and the axis of symmetry. (6) As a last suggestion, I recommend that, on another occasion, you try to animate the point in GeoGebra that symbolizes the rock in your problem.

It is convenient to specify that the evidence provided by the majority of MTITs, by way of forum comments, did not permit to relate their knowledge with analysis units TPACK2, TPACK3, TPACK4 and TPACK5. Consequently, it cannot be guaranteed that the participants possess these forms of knowledge.

\section{Conclusions}

To achieve the first specific objective, a classification system of indicators was designed that allows the study of teaching knowledge through the TPACK model by means of the compilation and analysis of works related to this archetype and the construction of the state of the art and theoretical framework. Furthermore, a validation process of these indicators was implemented; thus, it has been verified that they really permit to evidence the forms of knowledge that make up the model. In addition, for the process of establishing the units of analysis, issues such as errors when approaching the subject of quadratic function, the different semiotic representations and use of technology to develop the subject, among others, were taken into consideration, and this made possible to specifically adapt each unit of analysis to the context in which this research is carried out.

Regarding the second objective, it was possible to adapt an instrument that permits to broadly analyze the knowledge of future teachers as proposed by the TPACK model in relation to the content of the subject of quadratic function. It is necessary to emphasize that this instrument allows to analyze the forms of knowledge proposed by the TPACK model from three perspectives: the Diagnostic Questionnaire gauged the self-perception of the various forms of knowledge; the Assignment of Mathematical Tasks provided information to analyze these forms of knowledge during the execution of various tasks ranging from elementary procedures to more complex processes of the teaching activity, such as the design of activities and instruction guides; finally, the Reflection on the Analysis of Instructions made possible to analyze knowledge from the reflective practice of the teaching activity.

To accomplish the third specific objective, the information collected in the first and second objectives was used. The main conclusions for each form of knowledge proposed by the TPACK model are presented below. 
Technological knowledge: It was determined that most of the participants have an adequate attitude when using technology; however, they manifest insecurities about the implementation of ICTs for educational purposes. It was concluded that the participants possess the basic knowledge to manipulate dynamic geometry software such as GeoGebra and educational platforms such as Moodle, which are fundamental elements in the initial training of mathematics teachers [43]. However, the information obtained when reflecting on the implementation of the software in an activity for teaching the quadratic function was unclear and unfounded, that is, although MTITs possess knowledge about its use, it was insufficient to create a specific activity, from a technological point of view.

Pedagogical knowledge: It is concluded that these MTITs are aware of the importance of developing and including pedagogical skills during their initial training [44]. In addition, it was determined that participants know about strategies for the development of the class that seek to emphasize the modeling, construction and resolution of problems, which are processes proper of the development of mathematical thinking [14].

Content Knowledge: It can be assured that most of the participants understand the different characteristics of the quadratic function, are able to solve problems related to it and know how to algebraically manipulate the information to determine different elements. Nevertheless, it was observed that it is difficult for participants to delimit this content knowledge to a specific context which is a frequent error [45]. Likewise, participants present errors when defining the quadratic function, since they focus on the function's association criterion $[28,29]$.

Technological Pedagogical Knowledge: Although MTITs have knowledge and some proficiency in the utilization of software such as GeoGebra, this is not sufficient evidence to conclude that they can assertively integrate technology within mathematics classes [46]. It can be concluded that MTITs are aware that the use of technological tools influences the teaching and learning processes [47]; participants indicated that it is of importance to guide secondary education students in operating the software so that they can focus on developing mathematical knowledge skills, an idea that is supported by one of the contributions regarding TPK [37]. Nevertheless, there was little or no evidence on some aspects of TPK knowledge.

Pedagogical Content Knowledge: It was determined that participants are knowledgeable about some of the difficulties entailed in approaching this subject; the most voiced difficulty is the lack of connection between the semiotic representations of the quadratic function $[23,31]$. Participants also mention limitations $[29,33,48]$, regarding the study of this type of functions. One conclusion of the present work is that, although the majority of the participants perform the correct algebraic procedures to solve a problem related to a quadratic function, a large number of MTITs present errors when interpreting the calculations or elements of the function, which can be related to the techniques applied to solve problems in a mechanized manner so often promoted by teachers [25].

From the information analyzed pertaining to PCK, it was concluded that most teachers in training do not yet possess the ability to propose activities and create instructions that guide in detail the execution of tasks (with or without technology); further, it seems difficult for in training teachers to formulate questions to make the content accessible; hence, it is necessary to deepen this knowledge even more.

Technological Content Knowledge: It was determined that participants are aware that the use of technological tools in teaching and learning processes offers many advantages; however, they know that their implementation entails multiple challenges for institutions, teachers and students. In addition, MTITs understand that the incorrect use of ICTs can hinder the teaching and learning processes [49,50]. Most MTITs have the basic skills to render representations for educational purposes in GeoGebra software. Moreover, participants improve the interpretation of the elements of a function describing a particular context if they rely on a representation; nonetheless, a considerable number of participants showed difficulty in making the correct interpretation (obstacle on the conversion of semiotic representations $[23,31,50]$. 
Technological Pedagogical Content Knowledge: According to the analysis carried out, it was determined that few MTITs at an early stage of their training reached a certain level of integration between the three basic forms of knowledge of the model (three participants). Likewise, most participants have not yet developed an adequate level of critical reflection on the integration of all forms of knowledge involved in the TPACK model, although this deficiency was relatively expected considering the academic level at which MTITs are in.

The training of teachers is fundamental as they are the support to ensure the development and communication of children in later life. The teacher must have the ability to promote mathematical skills for a successful future of children in society. Thus, understanding the TPACK of future teachers is imperative in order to achieve these goals [51-54].

Thus, the main conclusion of this work is that even though MTITs have already had contact with courses related to general pedagogy, application of technological resources, and have studied the mathematical content, it cannot be ensured that their knowledge allows them to have a complete vision about the integration of technologies as a didactic resource in the teaching of functions.

\subsection{Research Limitations}

This research was not intended to generalize the results for all students of the Mathematics Teaching BLEM Program at the Universidad Nacional (i.e., MTITs), although it provides an overview of the knowledge that teachers in initial training possess at an early stage of training at this university.

Another limitation of the study was the lack of specific information that relates the content of functions with the TPACK model, since most of the investigations consulted as bibliographic references focus on the subject of Geometry. In addition, the fact that there is no prior research or diagnosis on the forms of knowledge possessed by secondyear (academic), in training mathematics teachers at the Universidad Nacional makes it impossible to triangulate the obtained results in greater depth.

\subsection{Recommendations for Future Research}

This study should be replicated longitudinally at the different levels of training in Mathematics Teaching degrees, to ascertain the evolution of teachers' TPACK knowledge during their training. This will make it possible to assess whether the requirements of the integration of pedagogical, technological and mathematical knowledge proposed by the UNA are being met (e.g., [6-8,10]). Finally, it will be necessary to carry out studies similar to this one, addressing other areas of mathematical knowledge (numbers, relations and algebra, statistics and probability), since the literature reviewed during the theoretical enquiry showed that research has focused mainly on the analysis of TPACK from the area of Geometry.

Supplementary Materials: The following are available online at in Zenodo at http:/ / doi.org/10.528 1/zenodo.4918062. In Supplementary 2, situation 1 appears in question 5 and situation 2 appears in question 8 .

Author Contributions: The authors (Y.M.-L., Y.C.-C., W.V.-D.) participated in all stages of the research process, as well as in the creation, writing and correction of the article in an equivalent manner. All authors have read and agreed to the published version of the manuscript.

Funding: This research and the APC were funded by UNIVERSIDAD NACIONAL, grant number COD 018133.

Institutional Review Board Statement: Not applicable.

Informed Consent Statement: Informed consent was obtained from all subjects involved in the study.

Data Availability Statement: Data supporting the results of this study will be made available by the corresponding authors Y.C.-C. and W.V.-D., upon reasonable request. 
Acknowledgments: The research was carried out in the context of (1) the project PGC2018-098603B-I00 (MCIU/AEI/FEDER, EU), (2) the Degree Programme of Universidad Nacional, Costa Rica (Y.C.-C. and W.V.-D.), (3) the PhD programme "Didàctica de les Ciències, les Llengües, les Arts i les Humanitats" of Universitat de Barcelona (Y.M.-L.), and (4) the international agreement UNA-UB: Cod 018133.

Conflicts of Interest: The authors declare no conflict of interest.

\section{References}

1. Bonafini, F.C.; Lee, Y. Investigating Prospective Teachers' TPACK and Their Use of Mathematical Action Technologies as They Create Screencast Video Lessons on IPads. Techtrends 2021, 65, 303-319. [CrossRef] [PubMed]

2. Shulman, L.S. Those Who Understand: Knowledge Growth in Teaching. Educ. Res. 1986, 15, 4-14. [CrossRef]

3. Shulman, L.S. Knowledge and Teaching: Foundations of the New Reform. Harv. Educ. Rev. 1987, 57, 1-23. [CrossRef]

4. Acikguel, K.; Aslaner, R. Effects of Geogebra Supported Micro Teaching Applications and Technological Pedagogical Content Knowledge (TPACK) Game Practices on the TPACK Levels of Prospective Teachers. Educ. Inf. Technol. 2020, 25, $2023-2047$. [CrossRef]

5. McBroom, E. Learning to teach geometry with technology: A case study of one in-service teacher's technological pedagogical content knowledge. In Proceedings of the E-Learn: World Conference on E-Learning in Corporate, Government, Healthcare, and Higher Education; Ho, C., Lin, M., Eds.; Association for the Advancement of Computing in Education (AACE): Honolulu, HI, USA, 2011; pp. 2427-2432. Available online: https:/ / www.learntechlib.org/primary/p/39093/ (accessed on 22 November 2019).

6. Wang, Q.; Zhao, G. ICT Self-Efficacy Mediates Most Effects of University ICT Support on Preservice Teachers' TPACK: Evidence from Three Normal Universities in China. Br. J. Educ. Technol. 2021. [CrossRef]

7. Marban, J.M.; Sintema, E.J. Pre-Service Teachers' TPACK and Attitudes toward Integration of ICT in Mathematics Teaching. Int. J. Technol. Math. Educ. 2021, 28, 37-46. [CrossRef]

8. Chai, C.S.; Rahmawati, Y.; Jong, M.S.-Y. Indonesian Science, Mathematics, and Engineering Preservice Teachers' Experiences in STEM-TPACK Design-Based Learning. Sustainability 2020, 12, 9050. [CrossRef]

9. Kapici, H.O.; Akcay, H. Improving Student Teachers' TPACK Self-Efficacy through Lesson Planning Practice in the Virtual Platform. Educ. Stud. 2020. [CrossRef]

10. Backfisch, I.; Lachner, A.; Hische, C.; Loose, F.; Scheiter, K. Professional Knowledge or Motivation? Investigating the Role of Teachers' Expertise on the Quality of Technology-Enhanced Lesson Plans. Learn. Instr. 2020, 66. [CrossRef]

11. Cam, S.S.; Koc, G.E. Technological Pedagogical Content Knowledge Practices in Higher Education: First Impressions of Preservice Teachers. Technol. Knowl. Learn. 2021, 26, 123-153. [CrossRef]

12. Alharbi, H.E. An Arabic Assessment Tool to Measure Technological Pedagogical and Content Knowledge. Comput. Educ. 2019, 142. [CrossRef]

13. Young, J.R.; Young, J.; Hamilton, C.; Pratt, S.S. Evaluating the Effects of Professional Development on Urban Mathematics Teachers TPACK Using Confidence Intervals. Redimat-Revista Investig. Didact. Mat. 2019, 8, 312-338. [CrossRef]

14. Font, V. Mathematics education. Trends and perspectives [Enseñanza de la matemática. Tendencias y perspectivas]. In Actas III Coloquio Internacional Sobre Enseñanza de las Matemáticas; Gaita, C., Ed.; Impresión PUCP: Lima, Peru, 2008; pp. 21-64. Available online: http:/ / repositorio.pucp.edu.pe/index/bitstream/handle/123456789/110142/Actas\%202008\%20papel_1.pdf?sequenc $\mathrm{e}=4 \#$ page $=34$ (accessed on 22 November 2019).

15. Godino, J.D.; Rivas, M.; Castro, W.F.; Konic, P. Developing mathematics teachers' competences for didactical analysis [Desarrollo de competencias para el análisis didáctico del profesor de matemáticas]. Revemat Rev. Eletrônica Educ. Mat. 2012, 7, 1-21. [CrossRef]

16. Mishra, P.; Koehler, J. Technological Pedagogical Content Knowledge: A Framework for Teacher Knowledge. Teach. Coll. Rec. 2006, 108, 1017-1054. Available online: http:/ / one2oneheights.pbworks.com/f/MISHRA_PUNYA.pdf (accessed on 22 November 2019). [CrossRef]

17. Morales-López, Y. Knowledge evidenced by prospective mathematics teachers when performing a task involving geometry, teaching and the use of technology. Acta Sci. 2019, 21, 75-92. [CrossRef]

18. Belfiori, V. Use of the tpack framework by mathematics teacher training students [Uso del marco tpack por alumnos de un profesorado de matemática]. In Acta Latinoamericana de Matemática Educativa; Comité Latinoamericano de Matemática Educativa A.C.: México D.F., Mexico, 2014; pp. 1733-1740. Available online: http:/ / funes.uniandes.edu.co/6059/1/BelfioriUsoDelMarcoA LME2014.pdf (accessed on 22 November 2019).

19. Kirikçilar, R.; Yildiz, A. Technological Pedagogical Content Knowledge (TPACK) Craft: Utilization of the TPACK When Designing the GeoGebra Activities. Acta Didact. Napoc. 2018, 11, 101-116. [CrossRef]

20. Arévalo-Duarte, M.A.; García-García, M.Á.; Hernández-Suárez, C.A. ICT competences of mathematics teachers in the framework of the TPACK model [Competencias TIC de los docentes de matemáticas en el marco del modelo TPACK]. Civilizar 2019, 19, 1-27. [CrossRef]

21. Koh, J.H.L.; Chai, C.S.; Tsai, C.C. Examining the technological pedagogical content knowledge of Singapore pre-service teachers with a large-scale survey. J. Comput. Assist. Learn. 2010, 26, 563-573. [CrossRef] 
22. Koehler, M.J.; Shin, T.S.; Mishra, P. How do we measure TPACK? Let me count the ways. In Educational Technology, Teacher Knowledge, and Classroom Impact: A Research Handbook on Frameworks and Approaches; Ronau, R., Ed.; IGI Global: Hershey, PA, USA, 2012; pp. 16-31. [CrossRef]

23. Duval, R. Registros de Representación Semiótica y Funcionamiento Cognitivo del Pensamiento. Ann. Didact. Sci. Cogn. 1993, 5, 37-65. Available online: http:/ / numerisation.irem.univ-mrs.fr/ST/IST93004/IST93004.pdf (accessed on 22 November 2019).

24. Duval, R. Semiotic Representation Registers and the Cognitive Functioning of Thought [Un Tema Crucial en la Educación Matemática: La Habilidad Para Cambiar el Registro de Representación]. Gac. Real Soc. Matemática Española 2006, 9, $143-168$. Available online: https: / /dialnet.unirioja.es/servlet/articulo?codigo=1984436 (accessed on 22 November 2019).

25. Prada-Núñez, R.; Hernández-Suarez, C.; Jaimes, L. Semiotic representation of the notion of function: Conceptions of students transitioning from high school to university. [Representación semiótica de la noción de función: Concepciones de los estudiantes que transitan del Colegio a la Universidad]. Panorama 2017, 11, 34-44. [CrossRef]

26. Dreyfus, T. Advanced mathematical thinking processes. In Advanced Mathematical Thinking; Tall, D., Ed.; Kluwer Academic Publisher: New York, NY, USA; Boston, DC, USA; Dordrecht, The Netherlands; London, UK; Moscow, Russia, 2002 ; pp. 25-41. [CrossRef]

27. Artigue, M. Teaching and Learning Elementary Analysis: What Can Be Learned from Didactic Research and Curricular Changes? [Enseñanza y Aprendizaje del Análisis Elemental: ¿Qué se Puede Aprender de las Investigaciones Didácticas y los Cambios Curriculares?]. Relime 1998, 1, 40-55. Available online: http:/ / funes.uniandes.edu.co/9584/ (accessed on 22 November 2019).

28. Díaz, J. The concept of function: Research and teaching [El concepto de función: Investigaciones y enseñanza]. In Memorias de la XVIII Semana Regional de Investigación y Docencia en Matemáticas; Rodríguez, E., Sosa, S., Luque, F., Robles, C., Urrea, M., Eds.; Editorial Universidad de Sonora: Sonora, Mexico, 2008; pp. 35-40.

29. Elia, I.; Panaoura, A.; Gagatsis, A.; Gravvani, K.; Spyrou, P. Exploring Different Aspects of the Understanding of Function: Toward a Four-Facet Model. Can. J. Sci. Math. Technol. Educ. 2008, 8, 49-69. [CrossRef]

30. Córdoba, L.; Díaz, M.; Haye, E.; Montenegro, F. Students' difficulties in articulating graphical and algebraic representations of linear and quadratic functions [Dificultades de los alumnos para articular representaciones gráficas y algebraicas de funciones lineales y cuadráticas]. In I Congreso de Educación Matemática de América Central y El Caribe; Morales, Y., Ramírez, A., Eds.; Cemacyc: Santo Domingo, República Dominicana, 2013; pp. 1-13. Available online: http:/ / funes.uniandes.edu.co/4072/ (accessed on 22 November 2019).

31. Even, R. Subject matter knowledge for teaching and the case of functions. Educ. Stud. Math. 1990, 21, 521-544. [CrossRef]

32. González, M.J.; Gómez, P.; Lupiáñez, L. Notes on cognitive analysis. MAD Module 3. In Apuntes Sobre Análisis Cognitivo. Módulo 3 de MAD; Universidad de los Andes: Bogotá, Colombia, 2013; Available online: http:/ / funes.uniandes.edu.co/2041/1/Apuntes Modulo3MAD.pdf (accessed on 14 June 2019).

33. Hu, Q.; Son, J.W.; Hodge, L. High school teachers' content knowledge and knowledge of students' errors about quadratic functions. In Proceedings of the 40th Annual Meeting of the North American Chapter of the International Group for the Psychology of Mathematics Education, Greenville, SC, USA, 15-18 November 2018; Hodges, T.E., Roy, G.J., Tyminski, A.M., Eds.; University of South Carolina \& Clemson University: Greenville, SC, USA, 2018.

34. Villalobos, L. Social research approaches and designs: Quantitative, qualitative and mixed. In Enfoques y Diseños de Investigación Social: Cuantitativos, Cualitativos y Mixtos; Editorial Universidad Estatal a Distancia. Colección General: San José, CR, USA, 2017.

35. Taylor, S.; Bogdan, R. Introduction to qualitative methods. In Introducción a Los Métodos Cualitativos, 3rd ed.; Paídos: Buenos Aires, Argentina, 2000. Available online: https: / / asodea.files.wordpress.com/2009/09/taylor-s-j-bogdan-r-metodologia-cualitativa .pdf (accessed on 14 June 2019).

36. Schmidt, D.A.; Baran, E.; Thompson, A.D.; Mishra, P.; Koehler, M.J.; Shin, T.S. Technological pedagogical content knowledge (TPACK): The development and validation of an assessment instrument for preservice teachers. J. Res. Technol. Educ. 2009, 42, 123-149. [CrossRef]

37. Önal, N. Development, Validity and Reliability of TPACK Scale with Pre-Service Mathematics Teachers. Int. Online J. Educ. Sci. 2016, 8, 1-15. Available online: https:/ /iojes.net/?mod=tammetin\&makaleadi=\&makaleurl=IOJES_2014.pdf\&key=40852 (accessed on 22 November 2019). [CrossRef]

38. Alpízar, M. Theory, exercises and some solutions. Basic notions of functions. In Teoría, Ejercicios y Algunas Soluciones. Nociones básicas de Funciones; Universidad Nacional: Heredia, CR, USA, 2019.

39. Bardin, L. Content analysis. In Análisis de Contenido, 2nd ed.; Ediciones Aka: Madrid, Spain, 1996.

40. Andréu, J. Content Analysis Techniques: An Updated Review [Las Técnicas de Análisis de Contenido: Una Revisión Actualizada]. Fund. Cent. Estud. Andal. 2002, 10,1-34. Available online: https://www.academia.edu/download/39429166/LAS_TECNICAS_ DE_ANALISIS_DE_CONTENIDOS.pdf (accessed on 22 November 2019).

41. Fernández, F. Content Analysis as a Methodological Aid to Research [El Análisis de Contenido Como Ayuda Metodológica Para la Investigación]. Rev. Cienc. Soc. 2002, 2, 35-53. Available online: https://www.redalyc.org/pdf/153/15309604.pdf (accessed on 14 June 2019).

42. Carter, N.; Bryant-Lukosius, D.; DiCenso, A.; Blythe, J.; Neville, A.J. The Use of Triangulation in Qualitative Research. Oncol. Nurs. Forum 2014, 41, 545-547. [CrossRef] 
43. Cabero, J.; Barroso, J.; Cadena, A.; Castaño, C.; Cukieman, U.; Llorente, M.; Gallego, O.; Pérez, M.; Jiménez, T.; Olazabalaga, I.; et al. Teacher training in ICT: The TPACK model. In La formación del Profesorado en TIC: Modelo TPACK; Universidad de Sevilla: Sevilla, Spain, 2014; Available online: https:/ / www.researchgate.net/publication/266733957_La_formacion_del_profesorado_en _TIC_modelo_TPACK (accessed on 14 June 2019).

44. Azcarate, M. Initial Mathematics Teacher Education: Analysis from the Perspective of Professional Know-How [La Formación Inicial del Profesor de Matemáticas: Análisis Desde la Perspectiva del Conocimiento Práctico Profesional]. Rev. Interuniv. Form. Profr. 1998, 32, 12-132. Available online: https:/ / dialnet.unirioja.es/servlet/articulo?codigo=117983 (accessed on 14 June 2019).

45. Zúñiga, L.; Melba, I. A Study on the Construction of the Concept of Function, Visualisation in Students of a Calculus I Course. [Un Estudio Acerca de la Construcción del Concepto de Función, Visualización en Alumnos de un Curso de Cálculo I]. Master's Thesis, Universidad Pedagógica Nacional Francisco, Morazán, Tegucigalpa, 2009. Available online: http:/ / www.cervantesvirtual.com/descargaPdf/un-estudio-acerca-de-la-construccion-del-concepto-de-funcion-visualizacio n-en-alumnos-de-un-curso-de-calculo-i/ (accessed on 14 June 2019).

46. Gómez-Chacón, I.; Joglar, N. Developing Competencies to Teach Exponential and Logarithmic Functions Using GeoGebra from a Holistic Approach. Educ. Mat. Pesqui. 2010, 12, 485-513. Available online: https://revistas.pucsp.br/index.php/emp/article/vi ew /4644 (accessed on 14 June 2019).

47. Alfonzo, Z. Computer-Aided Didactics of Linear and Quadratic Functions [Didáctica de las Funciones Lineales y Cuadráticas Asistidas con Computadora]. Rev. Didasc@Lia Didáctica Educ. 2012, 3, 2224-2643. Available online: https://dialnet.unirioja.es/se rvlet/articulo?codigo=4230477 (accessed on 14 June 2019).

48. Zaslavsky, O. Conceptual obstacles in the learning of quadratic functions. Focus Learn. Probl. Math. 1997, 19, 20-44.

49. Torres, A.; Gilbert, R. Use of technology in algebra teaching [Empleo de la tecnología en la enseñanza del álgebra]. In Acta Latinoamericana de Matemática Educativa; Lestón, P., Ed.; Colegio Mexicano de Matemática Educativa A. C. y Comité Latinoamericano de Matemática Educativa A.C.: México, D.F., Mexico, 2010; pp. 1153-1160.

50. Slavíčková, M. Implementation of Digital Technologies into Pre-Service Mathematics Teacher Preparation. Mathematics 2021, 9 , 1319. [CrossRef]

51. Papadakis, S.; Kalogiannakis, M.; Zaranis, N. Teaching mathematics with mobile devices and the Realistic Mathematical Education (RME) approach in kindergarten. Amler 2021, 1, 5-18. [CrossRef]

52. Pincheira, N.; Vásquez, C.; Giacomone, B. An Approach to Didactic-Mathematical Knowledge of Future Basic Education Teachers to Teach Elementary Mathematics. Uniciencia 2021, 35. [CrossRef]

53. Esqué de los ojos, D.; Breda, A. Assessment and Redesign of a Unit on Proportionality Using the Didactical Suitability Tool. Uniciencia 2021, 35. [CrossRef]

54. Sánchez, A.; Font, V.; Breda, A. Significance of Creativity and Its Development in Mathematics Classes for Preservice Teachers Who Are Not Trained to Develop Students' Creativity. Math. Educ. Res. J. 2021. [CrossRef] 